\title{
Prevention or delay of gastritis through vestibular stimulation: A hypothesis
}

\author{
Kumar Sai Sailesh ${ }^{1}$, Archana R ${ }^{3}$, Navya Jith Jacob ${ }^{1}$, Sneha V George ${ }^{1}$, Reena Johndas ${ }^{1}$, Minu Johny ${ }^{1}$, MariaJoseph ${ }^{1}$, Ayana Joy ${ }^{1}$ and Mukkadan JK ${ }^{2 *}$ \\ ${ }^{1}$ Little Flower Institute of Medical Sciences and Research, Kerala, India \\ ${ }^{2}$ Little Flower Medical Research Centre, Angamaly, Kerala, India \\ ${ }^{3}$ Saveetha Medical College, Saveetha University, Chennai, India
}

\begin{abstract}
Gastritis is inflammation of the lining of the stomach. It may be short episode or may be of a long duration. The most common symptom is upper abdominal pain. Other symptoms include nausea and vomiting, bloating, loss of appetite, and heart burn. Gastritis is believed to affect about half of people and as people becomes aged the prevalence increases. Chronic gastritis is associated with ulcers and may increase risk for stomach cancer. Vestibular apparatus is located in the inner ear and helps for maintenance of balance and equilibrium. However, stimulating vestibular system in a controlled manner was found very beneficial and could prevent endocrine disorders like diabetes, hypothyroidism and relieves stress and anxiety. Natural method of stimulating vestibular system is by swinging on a swing according to the comfort. Aparna Sarkar and Debjani Guha et al., testified that vestibular stimulation effectively reduced secretion of acid from the stomach in animals and recommended vestibular stimulation as a natural therapy for gastric disorders. Hence there is a need to identify the need of vestibular stimulation and to conduct similar studies in human beings to validate vestibular stimulation in the treatment of gastric disorders.
\end{abstract}

\section{Introduction}

Gastritis is inflammation of the gastric mucosa [1]. The etiological factors of gastritis were Helicobacter pylori infection, nonsteroidal antiinflammatory drugs (NSAIDs) and autoimmunity. Other causative factors of gastritis are drugs, life style changes, life habits and stress [2]. Frequent use of analgesics, anti-rheumatics and antibiotics, less physical activity, consumption of spicy or starchy food, use of alcohol, missing or delaying meals are some of the risk factors associated [3]. Gastritis may be classified in to acute gastritis and chronic gastritis. Histologic evidence of acute gastritis (inflammation) are asymptomatic. Acute gastritis may present with an array of symptoms which include epigastric discomfort, loss of appetite, nausea, vomiting, belching, and bloating. Occasionally, acute abdominal pain can be a presenting symptom. Vomiting of potentially purulent gastric contents can be also seen. Fever, chills, and hiccups also may be present. The prevalence of gastritis in India is 1,065,070,607 (population estimated used). Studies reported that prevalence rate ranges from less than $15 \%$ to $100 \%$ depending upon their socio-economic condition [4]. The risk and rate of acquisition is highest in early childhood, after which the rate exponentially declines. Vestibular system consists of three semicircular canals and otolith organ which is embedded in the bony cavity of the temporal bone [5]. Controlled vestibular stimulation can be provided by swinging on swing which is an effective method for relieving the pain, stress and treat endocrine disorders. So vestibular stimulation is effective for relieves stress and anxiety. Here we review the possible pathways through which vestibular stimulation may prevent/delay the gastritis.

\section{Vestibular stimulation may prevent or delay gastritis through relieving stress}

Gastric parietal cell secretion is depressed by enhanced sympathetic nerves activity [6]. In a stressed situation immune system becomes less capable of handling the germs around, fighter soldier cells (white blood cells) are less active in the lining of the stomach to kill the germs (H. pylori) which allows the germs to penetrate the lining and the deeper layers of the stomach [7]. The parasympathetic (Valgus nerve) stimulates production of hydrochloric acid through release of a local hormone (Gastrin), from the lower end of the stomach (pylorus) and acid producing oxyntic cells of the stomach lining. Vestibular stimulation inhibits the stress axes and HPA axes directly and indirectly and brings stress to a less condition. Hence, we hypothesized that vestibular stimulation may be beneficial in relieving most of the symptoms of gastritis [8].

\section{Vestibular stimulation may prevent or delay gastritis by promoting sleep}

Insomnia is found among people with Gastritis, especially for people who are female, $60+$ old, take medication Omeprazole and have Gastritis. Studies show that, in chronic insomnia, the activity of the HPA axis and the sympathetic system relates positively to the degree of objective sleep disturbance [9]. Increased stress level cause lack of sleep and it also promote increased gastric secretion. This article is to review that by reducing the stress level can reduce the gastric secretion. Vestibular stimulation is an effective intervention for relieving the stress there by improving the sleep $[8,10]$.

Correspondence to: Dr. J K Mukkadan, Research Director, Little Flower Medical research Centre, Angamaly, Kerala, India, E-mail: drmukkadan@gmail.com

Key words: vestibular stimulation, gastritis, natural therapy

Received: September 01, 2016; Accepted: September 30, 2016; Published: October 04, 2016 


\section{Conclusion}

We have provided the possible mechanisms by which vestibular stimulation effects gastric secretion. Though animal studies are supporting our hypothesis, we suggest the researchers to conduct human studies to provide scientific evidence for beneficial effects of vestibular stimulation as a supplementary treatment for gastritis.

\section{References}

1. Hungampola OGPRCL, Samarakoon SMC, Perera DACD, Perera HAMS, De Silva BSS, et al. (2013) Factors influencing gastritis: a preliminary study for assessment of knowledge, attitudes and practices among patients with gastritis. 229.

2. Heitkemper L (2000). Medical surgical Nursing (4th Ed).

3. Waidyarathne EI, Lekamwasam, JDVC, Gunawardana H, Muddawa LKB, et al. (2008) Risk \& protective factors of chronic gastritis in a group of patient undergoing upper gastrointestinal endoscopy: a case control study. Gall Research network free paper session, Faculty of Medicine; Galle.

4. Alenezy Awwad KA, Hassan Taha M M (2014) Heliclobacter pylori associated chronic gastritis: Endoscopic and pathological findings, Comparative study. International Journal of Genetics and Molecular Biology 6: 23-28.
5. Guyton, Hall (2013) Textbook of medical physiology (13th Ed) 1673-1695.

6. Hodge AJ, Masarei JR, Catchpole BN (1972) The role of the sympathetic nervous system in hypoglycaemia-stimulated gastric secretion. Gut 13: 341-345. [crossref]

7. Spirt MJ (2004) Stress-related mucosal disease: risk factors and prophylactic therapy. Clin Ther 26: 197-213. [crossref]

8. Sailesh KS, R A, J K M (2014) Controlled vestibular stimulation: a physiological method of stress relief. J Clin Diagn Res 8: BM01-02. [crossref]

9. Vgontzas AN, Tsigos C, Bixler EO, Stratakis CA, Zachman K, et al. (1998) Chronic insomnia and activity of the stress system: a preliminary study. $J$ Psychosom Res 45 : 21-31. [crossref]

10. Kumar SS, Rajagopalan A, Mukkadan JK (2016) Vestibular Stimulation for Stress Management in Students. J Clin Diagn Res 10: CC27-31. [crossref]

11. Sailesh KS, Mukkadan JK (2015) Controlled vestibular stimulation, standardization of a physiological method to release stress in college students. Indian J Physiol Pharmacol 59: 436-441.

12. Sailesh KS, Archana R, Antony NJ, Mukkadan JK (2014) Controlled vestibular stimulation: Supplementary treatment for hypothyroidism. Res J Pharm Biol Chem Sci 5: 1842-1845.

13. Nagarathna R. Yoga for Digestive Disorders. Health and Yoga.

Copyright: $₫ 2016$ Sailesh KS. This is an open-access article distributed under the terms of the Creative Commons Attribution License, which permits unrestricted use, distribution, and reproduction in any medium, provided the original author and source are credited. 